\title{
Contribution of time management and locus of control on student academic prograstination
}

\author{
Muhammad Sulaiman ${ }^{1}$, Syahniar ${ }^{2}$, Daharnis $^{3}$ \\ ${ }^{123}$ Universitas Negeri Padang, Padang - Indonesia, (sulaimanolo621@gmail.com)
}

\begin{abstract}
This study aims to determine the contribution of time management to student academic procrastination, contribution of locus control to student academic procrastination, and contribution of time management and locus of control to academic procrastination of UMSU Medan students. Types of quantitative research correlational approaches. The population are 180 undergraduate students of UMSU Medan. Sample 124 people with stratified proportional random sampling technique. The instrument used is Likert scale. The reabilty of instrument 0,955 . Research data were analyzed by simple regression and multiple regression. The result of the research shows that the ability of time management with medium category, the tendency locus of control with medium category, low academic procrastination level, time management contribute significantly to academic procrastination, locus of control contribute significantly to academic procrastination, time management and locus of control jointly contribute 20,6\% significantly to the academic procrastination of students at UMSU Medan.
\end{abstract}

Keywords: time management, locus of control, procrastination.

This is an open access article distributed under the Creative Commons 4.0 Attribution License, which permits unrestricted use, distribution, and reproduction in any medium, provided the original work is properly cited. (C2018 by author and Faculty of education, Universitas Negeri Padang.

\section{Introduction}

Ideally the student must have the independence of learning to achieve maturity to form himself a student of knowledge and noble character. Learning is an obligation that students must meet in college. Students are required to have good learning management in doing the tasks given by lecturers. The number of tasks and activities undertaken by students will require the ability to utilize the time well.

Procrastination of work is known as procrastination. Ferrari (Zulna, 2013) finds that academic procrastination is a kind of procrastination that is done on the kind of formal task associated with academic tasks. Silver (Ghufron \& Risnawita 2012), a procrastinator does not intend to avoid or do not want to know the task at hand, but they just procrastinate to do it so that it takes the time it takes to complete the task. Such delays often result in him failing to complete tasks on time. Rumiani

(in Daharnis, 2017) The delay in completing this academic task is called academic procrastination.

Individuals who succeed in learning, need to do the job as well as possible. This explains that the success of students in learning, especially in completing the task should be able to take advantage time optimally (Slameto, 2003). However, the reality is still a lot of students who have not been able to 
manage the learning time effectively and efficiently. This, will cause the student to delay in completing the task that will be done. This is called academic procrastination. Noran, (Akinsola, Tella \& Tella, 2007: 364-365) explains "Considers a procrastinator as someone who knows what he is doing, is doing and performing task, but does not complete the task, or excessively delays performing the task ". That is, the procrastinator is the individual who knows exactly what he wants to do, ready to complete the task, try and plan to run the task, but does not complete the task, or excessively make the delay to complete the task.

Academic procrastination is a deliberate and repetitive delays in completing a task or job, either starting or completing a task related to the academic field (Muhid, 2012). Procrastination can be seen in many ways because it involves various elements of complex problems, which are interconnected with each other. Procrastination is not only a description of the low learning habits or time management, but also involves interaction which are so complex of behavioral, cognitive, and affective components. Solomon \& Rothblum (Ackerman \& Gross, 2005: 5) found that students accustomed to delays believe that the tendency to procrastinate, significantly disrupts academic achievement, the ability to master class materials and quality of life.

Ferrari \& McCown (Purnamasari 2014) academic procrastination has many negative consequences and is an important issue that needs to get attention because it affects the students themselves and for others or the environment in the form of results that are not optimal. Rumiani (2006: 38) procrastination that occurs in the academic environment called academic procrastination. Furthermore, Senecal, Koestner, \& Vallerand (in Gohil, 2014: 92) "Academic procrastination can be understood as knowing that one is supposed to be able to do so. desired time frame ". That is, academic procrastination can be understood as one of the delays that it should or may wish to do, complete the academic task but fail to do so, within the expected or desired timeframe. Beswick, Rothblum, \& Mann (1988: 207) explains "Academic procrastination is a tendency to postpone academic tasks and the delay makes students experience anxiety related to delays that have been done". Ackerman \& Gross (2005: 5) found that "Students who are accustomed to postponing believe that the tendency to perform procrastination will significantly interfere with academic achievement, as well as the ability to master classroom material to quality of life". It is concluded that academic procrastination is often performed by students at the present time for each subject area given by the lecturer, so in the learning process the postponement attitude has become commonplace for the students.

Continuous procrastination behavior will foster indiscipline in the in dividual, the quality of human resources produced will also be lower. Ellis \& Knaus (1977) found that 95\% of American students do procrastination. Later on, the results of a survey by Solomon, L. J. \& Rothblum (1984) found that $50 \%$ of students reported that students delayed academic duties at least half the time and an additional 38\% reported delaying occasionally.Furthermore, Ferrari (Ghufron, 2010: 158) also explains delay behavior can be manifested in certain indicators that can be measured and observed its characteristics, which are divided into four characteristics, namely: (1) delay for initiating or completing work on the task at hand, (2) delays in doing the task, (3) the time gap between the plan and the actual performance, and (4) doing other activities more fun than doing the task to be done.

Solomon \& Rothblum (1984: 504) explains that academic procrastination is common in six task areas, namely; (1) writing a term paper, (2) studying for an exam, (3) reading (keeping up with weekly reading assignments), (4) administrative (performing administrative tasks), (5) attending meetings, and (6) the overall academic tasks in general. Rotter (Loice, 2014: 02) explains "Locus of control as the extent to which people perceive that they are in control of the events that influence their lives". That is, the locus of control is the extent to which a person feels that he or herself (external factors) such as opportunity and other power, can control the events that occur and affect their lives. 
The locus of control consists of two dimensions, internal and external, students with a tendency to locus of internal controls that their success and failure in learning are the result of their own actions and efforts (Rotter, J. B, 1966). For example when the student has a low score, believes that he did not learn optimally, not because his teacher is favoritism. Conversely, students who have an external locus of control tendency will believe that success and failure are due to factors outside of himself. Syafaruddin \& Irwan (2005: 7) explains that "Management is the process of obtaining action through the efforts of others". The meaning of management is the main force in organizations that coordinate the various activities of the parts (sub-systems) and related to the environment. Management is a process of combining unrelated resources into the whole system for achieving goals. Management seeks to focus attention on key administrative processes including planning, organizing, and monitoring that are essential if the organization wants to achieve its ultimate goals and objectives. Further, explained Syafaruddin \& Irwan (2005: 16) "that managerial activity takes place in business organizations, government, education, social and other organizations where the human element and physical resources combined to achieve the goals to be achieved".

Macan, TH (1994) says that time management is self-regulation in using time as effectively and efficiently as possible by planning, scheduling, having control over time, always making priority scale according to importance, and the desire to be organized that can be seen from behavior such as arranging places work and do not procrastinate work. Wilkinson (Timpe, 2004: 11) states that if someone who regulates life and makes it fun, for the necessary start is to manage time or manage time well, unquestionably in effective time management is a fundamental activity in the sphere of life. In fact, there is often a distinction between the attainment of true life and the busy person, never reaching any point, if in all the educational activities the timing becomes a necessity. If we look more closely it will be seen that the actual time setting is not much different from self-management. In fact, if it can not manage or manage time, it can manage itself at every opportunity. Most experts agree that success is the result of habit.

Several studies have tried to measure the relationship of procrastination and time management. Lay (Van Eerde, 2003) found a negative correlation between procrastination trait and Time Management Behavior Scale (TMBS) subscale found no correlation, but obtained clear results that procrastinators use less time management than non procrastinators. Show that time management training can reduce worries and procrastination in work. However, further discussion indicates the possibility that training only serves as a catalyst (an auxiliary that can help the effect) on the impact of decreasing procrastination and concerns. It is said that time management training may only increase a person's awareness of his or her behavior in general.

This is in line with the results of research conducted Nugrasanti (2006) about the relationship between locus of control and academic procrastination on the students, the results of the correlation between the two variables showed a significant relationship that the more external locus of control students, the higher the tendency of academic procrastination conducted college student. Based on the conclusion some of the above research results can be concluded student must have internal locus of control and locus of control external good and stable because if high locus of control will decrease procratination academic student.

Locus of control was first presented by Rotter "The concept of locus of control is part of social learning theory that concerns personality and represents the general expectation of the problem factors determining the success of praise and punishment for one's life." (Pervin, in Smet, 1994: 181).

Furthermore, Lau (1988: 52) defines the locus of control as "self-control related to matters concerning the behavioral issues of the individual concerned". Individuals with high self-control will see that they are able to control their behavior (locus of control internally). This opinion is supported 
by Sarafino (1990: 114) which states that individuals with internal locus of control believe that success and failure that occur in life depends on yourself. A teenager who has an external locus of control has a belief that the controller of all aspects of his life and the boost he receives is luck, fate, or others outside him (Wulan 1994: 2). Rotter (in Daharnis, 2017) reveals the characteristics of the internal locus of control of learners, among others: full attention to something, competent, able to fight and overcome outside influences, achievement oriented, nimble, and believe in their own ability. Walker (2001: 11) says the locus of control refers to the individual's belief that he is responsible for the outcome he receives. Mappiare (2006: 24) defines that the locus of control in the term counseling terminology is "One's view of the controlling power in his life, whether internal control or external control".

Furthermore, Crider (in Pure 2012: 22) reveals other positive personality traits possessed by the individual tendencies of the internal locus of control, namely: hardworking, high initiative, always trying to find problem solving, always trying to think as effectively as possible, always have the perception that should try if it wants to succeed. Further Zulkaida, et al (2007: 33) said that the characteristics of individuals who have internal locus of control, among others; has the belief that the event of his life is the result of internal factors (individual beliefs of his abilities and skills), as well as the individual's responsibility has a willingness to accept everything as a cause of his attitude or behavior and seek to improve his attitude or behavior in order to achieve better results, and expectation (the individual begins a subjective judgment or expectation that positive consequences will be gained in certain situations in return for his behavior).

The purpose of this study is to describe: 1) Time management students at the University of Muhammadiyah North Sumatra. 2) Locus of control of students at Muhammadiyah University of North Sumatra. 3) Procrastination of academic students at Muhammadiyah University of North Sumatra. 4) The contribution of time management to student academic procrastination at Muhammadiyah University of North Sumatra. 5) Contribution of locus of control to student academic procrastination at Muhammadiyah University of North Sumatra. 6) Contributing time management and locus of control collectively to student academic procrastination at Muhammadiyah University of North Sumatra.

\section{Method}

This type of research includes quantitative research, with a correlational approach. The population of this research is S1 students of UMSU Counseling and Counseling Medan which amounts to 180 students. The sample was obtained by 124 students taken by proportional stratified random sampling technique. The instrument used in this research is a questionnaire with Likert model scale. The instrument used is inventory and Likert model scale. Research data were analyzed by using simple regression and multiple regression. Data collection techniques in this study using a questionnaire developed by researchers related to time management, locus of control, and academic procrastination.

\section{Result and Discussion}

This chapter presents the results of research and discussion on the contribution of time management and locus of control to student academic procrastination. The results of research and discussion based on the results of research scores that have been administered to students who become the sample of S1 Guidance and Counseling Faculty of Teacher Training and Education University of Muhammadiyah Sumatera Utara Medan. Based on the verification of research data, obtained data to be processed as much as 124 students (all samples). The data of this study include: 
time management (X1) locus of control (X2), and academic procrastination (Y). Can be described as follows:

Overall, the number of Student Time Management statements is 37 points. Based on the categories described in Chapter III, the overall student time management inventory can be found in Table 1 .

Table 1. Frequency Distribution and Percentage of Time Management (X1) by Category

$$
(n=124)
$$

\begin{tabular}{|c|c|c|c|}
\hline Category & Interval Skor & $\mathbf{F}$ & $\%$ \\
\hline Very High & $\geq 157$ & 0 & 0 \\
\hline High & $127-156$ & 48 & 39 \\
\hline Medium & $97-126$ & 75 & 60 \\
\hline Low & $67-96$ & 1 & 1 \\
\hline Very Low & $\leq 66$ & 0 & 0 \\
\hline \multicolumn{2}{|c|}{ Overall } & 124 & 100 \\
\hline
\end{tabular}

Based on Table 1, it shows that on average, the management of student time under S1 Guidance and Counseling FKIP UMSU Medan, dominated by medium category with percentage of $60 \%$, but some students also in high category with percentage of $39 \%$. This means that some students are still not able to manage time in daily activities.

Overall, the number of points of the scale of the locus of control is 23 points statement. Based on the classification of the category of locus of control scale described in Chapter III, the categorization of the locus of control scale can be seen in Table 2 .

Table 2. Distribution and Percentage (X2) Based Locus of Control Category $(\mathrm{n}=124)$

\begin{tabular}{|c|c|c|c|}
\hline Category & Interval Skor & $\mathbf{F}$ & $\%$ \\
\hline Very High & $\geq 107$ & 4 & 3 \\
\hline Height & $85-106$ & 54 & 44 \\
\hline Medium & $63-84$ & 56 & 45 \\
\hline Low & $41-62$ & 9 & 7 \\
\hline Very Low & $\leq 40$ & 1 & 1 \\
\hline & & 124 & 100 \\
\hline
\end{tabular}

Based on Table 2, it is seen that the locus of control S1 Guidance and Counseling FKIP UMSU Medan is in the category of being, with a percentage of $45 \%$. However, there is still a variation of locus of control score.

Overall, the number of statements of student academic procrastination variable is 45 points. Based on the interval formula described in Chapter III, the overall academic procurement scores of students as follows:

Table 3. Frequency Distribution and Percentage of Academic Procrastination (Y) by Category $(n=124)$

\begin{tabular}{|c|c|c|c|}
\hline Category & Interval Skor & $F$ & $\%$ \\
\hline Very Height & $\geq 187$ & 0 & 0 \\
\hline Height & $152-186$ & 2 & 2 \\
\hline Medium & 116-151 & 52 & 42 \\
\hline Low & $81-115$ & 65 & 52 \\
\hline Very Low & $\leq 80$ & 5 & 4 \\
\hline Overall & & 124 & 100 \\
\hline
\end{tabular}


Based on Table 3, it shows that undergraduate students of FKIP UMSU Guidance and Counseling, Medan is still doing academic procrastination, it is proven with the achievement of $52 \%$ score, that is in low category. More detailed description of academic procrastination based on indicators can show that the indicator of academic procrastination under S1 Guidance and Counseling FKIP, UMSU, Medan overall is in low category with achievement level of $50.4 \%$. Seen in each indicator still have medium and high category. On indicators that scored low on indicators of tendency to do fun things with when experiencing difficulties and even avoid inconvenience level of achievement of $46 \%$ and indicators The tendency to blame at the achievement level of $45.86 \%$ and indicators tendency to procrastinate things to do is in the moderate category with the achievement rate of $55 \%$ of the overall indicator need to be handled so that all students can reduce the behavior of academic procrastination.

\section{Discussion}

Based on the results of hypothesis test that has been described, then time management and the control of control contribute to academic procreation of $20.6 \%$. In the following sections, we will explain the discussion for each of the variables studied in the study, among them as follows.

The results showed that on average time management of students are in the medium category. This means that some students still have an inability to manage and make the best use of time, and students also believe that what is achieved in their life including in learning achievement is the result of their ability to manage and make the best possible time, while Planning and Scheduling medium, and the ability to control time including the medium category.

In fact, if someone who regulates life and makes it fun, as a necessary starting point is to manage time or manage time well, unquestionably in effective time management is a fundamental activity in the sphere of life. In reality, there is often a difference between a real life achiever and a busy person, never at any point, if in all the educational activities the timing becomes a necessity. However, if we look more closely it will be seen that the actual time setting is not much different from selfmanagement. In fact, if you can not manage or manage time, but can manage yourself on every occasion most experts agree that success is the result of habit.

The results showed that the locus of control of students on average was in the medium category. Students with external locus of control tend to be less effortful, less persistent, passive, and succumb to fate / destiny. All of which will result in low activity and quality of student learning activities. Zulkaida, et al (2007: 33) said that the characteristics of individuals who have internal locus of control, among others; has the belief that the event of his life is the result of internal factors (individual beliefs of his abilities and skills), as well as the individual's responsibility has a willingness to accept everything as a cause of his attitude or behavior and seek to improve his attitude or behavior in order to achieve better results, and expectation (the individual begins a subjective judgment or expectation that positive consequences will be gained in certain situations as a reward for his behavior).

The results showed that the average level of procrastination by students is in the low category. That is, the students are still doing academic procreation on the campus, such as delay in doing the task. The results of descriptive analysis of data indicate that the trend indicator delaying doing the things to be done is in the high category, while the indicator of the tendency to do the fun is in the medium category while the indicator of the tendency to blame is in the low category.

Research conducted by Statement by Knaus (Cu \& Choi, 2005) for procratination subject is delayed the results are done negatively. Someone will waste time in planning and wait for the right decision. 
Although the information considered to be the right decision-making element finally does not arrive, the individual sees it as important. Prohaska, Iraida, \& Perez (2000) that the procrastinators started their work at the last minute. Individuals can finish in time and they tend to work better and faster. Not infrequently they think more have a creative idea in conditions of time pressure. Their ideas are sometimes too good compared to the time available. Not infrequently they claim to do better, when they are given enough time or there is additional time again. Unwelcome tasks are left out, when the task completion time is no longer possible to avoid.

The results of this study are relevant to the results of research Sagita (2015) which shows on the description of academic procrastination data of students are in the category of being. Academic exclusion is delays conducted deliberately and continuously done in completing tasks, both to start and complete tasks related to academics (Ghufron \& Risnawati, 2014). Academic cultivation is a deliberate and continuous delays in completing a task or job, both to initiate and to complete tasks related to the academic field (Ghufron \& Risnawati, 2014). students become a strategy when dealing with problems or situations that cause stress. Students many fail in doing the task because of the delay they are doing.

Delays in the task will have a negative impact on students who are often called dysfunctional procrastination, that is, if the students delay procrastinating the task does not have a definite purpose and a lot of neglect of time, it can be detrimental to the students themselves especially in learning activities. However, this delay can be in a positive direction often called functional procrastination, if the delay is accompanied by a strong reason, has a definite purpose so as not to harm. In fact, it is useful to make a constructive effort to get a task done properly (Risnawita \& Ghufron, 2014).

The results of UMSU students' academic procrastination as a whole are classified as low category. This means explaining UMSU students are still experiencing academic procrastination that can disrupt the learning process so that it becomes ineffective and efficient. This problem will become more complex if not resolved. Then, in the high category need to be more in-depth handling

students can direct procrastination to the positive. Given the frequent occurrence of student academic procrastination, these findings should be followed up by lecturers / counselors to direct students to reduce high procrastination and lead the behavior of academic procrastination into a more positive direction through various counseling services provided to students.

Based on the research findings, that time management contributes significantly to academic procrastination. This means that the higher and better student time management the lower the academic procrastination, the student who sees that his life is determined by his own behavior where the student is able to make the best time possible in reaching his goal as in learning, because by believing that every effort done will get expected results, both in achieving and performing tasks on time, will be able to reduce student procrastination behavior. Students who have the confidence that they participate influence all the results achieved in life, of course also has the power in achieving the desired achievement.

In line with Hartosudjono (2012) study, the findings illustrate that why a person likes to do procrastination behavior: First, the lack of time management or less can prioritize time. Second, the material work is high at a little time. The high or the number of workers should be done, but the time available is not much. The priority of work to be done arose unexpectedly, causing what has been planned to be unattainable. Third, anxiety resolves the task. The time to complete the task is spent on facing anxiety or fear; but the individual just does not start his job. Fourth, do not know how to start or what it takes to complete the job. Fifth, too focused on failure or not meeting the standards that must be achieved. Sixth, perfection to achieve unrealistic standards. Seventh, bored by the task. 
Boredom against the routine of a task or a response, that the failure of the task to be done becomes a disaster. Eight, accustomed to avoiding difficult work.

This study discusses about, time management, locus of control, and academic procrastination targeted by students Guidance and Counseling FKIP UMSU Medan In principle, this research has been implemented optimally with reference to the method and the correct scientific procedures. However, the perfection of the results obtained is not easy to be realized. Researchers realize that this study is inseparable from the limitations and weaknesses that can not be avoided. Limitations in this research can be put forward as follows: 1) Variables in this study only discusses two factors only, for further research, should be done development with other factors that also have contribution to student academic procrastination. 2) The results of this study (time management and locus of control, and academic procrastination) are non-permanent or non-permanent, requiring efforts or actions of handling and follow-up so that the students can lead to time management and locus of control, good and normal as well academic procrastination in the low direction benefits both himself and others. 3) Data collection in this study using inventory locus of control and Licert model scale directed to students. Therefore, for the next researcher needs to be deepening with various other data collection methods or by using different types of research.

\section{Conclusions}

Based on the findings and discussion of research results, it can be concluded as follows: 1) The ability of student time management on average is in the category of being. This means that some students still have an inability to manage and make the most of their time. 2) The tendency of student locus of control is on average in the medium category. This means that students still believe that befall him is determined by the student itself. 3) The level of student academic procrastination on average is in the low category. That is, there are still students who procrastinate when doing the task given by the lecturer. 4) Time management contributes significantly to student academic procrastination. This suggests that to reduce student academic procreation requires high time management. 5) Locus of control contributes significantly to student academic procrastination. This, indicates that to reduce student academic procrastination required a high locus of control. 6) Time management and locus of control jointly contribute negatively to academic procrastination.

\section{References}

Ackerman, D., \& Gross, B. L. (2005). "My Instructor Made Me Do It: The Task of Characteristics of Procrastination". Journal of Marketing Education, 27 (3): 5-13.

Akinsola, M. K., Tella, A., \& Tella, A. (2007). "Correlates of Academic Procrastination and Mathematics Achievement of University Undergraduate Students". Eurasian Journal of Mathematics, Science and Technology Education, 3 (4): 363-370.

$\mathrm{Chu}$, angela Hsin Chun; Jin Nam Choi. (2005). Rethinking Procrastination: Positive Effects of "Active"

Daharnis. (2017). "The relationship between Locus of Control and Student's Perception on Education and Learning Motivation and Its Implication in Guidance and Counseling Service". Insight Journal: Guidance and Counseling Volume 2: 185-196.

Daharnis, 2017. "Relationship of Self Efficacy, Achievement Motivation, Academic Procrastination and Student Academic Steres". Journal of Bikotetik (Guidance and Counseling: Theory and Practice) Volume 1: 43-52.

Procrastination Behavior on Attitudes and Performance. The Journal of Social Psychology; Jun 2005; 145.3; ProQuest Psychology Journals.

Ellis, A, \& Knaus, W. J. (1977). Overcoming Procrastination. New York: Institute for Rational Living. 
Ferrari, Zulna (2013). Procrastination \& Task Avoidance: Theory, research, and treatment. New York: Plenum Press.

Hartanto, D. (2012). Troubleshooting Cheats. Yogyakarta: Jakarta Index.

Macan, T. H. (1994). Time Management: Test of process model. Journal of Appliet Psychology. New York: Plenum. Press.22 (4): 301-305.

Purnamasari, E. T. (2014). Relationship Between Personal Regulation and Procrastination Complete the Tasks of a Practical Subject Assistant. Thesis. Surakarta: Faculty of Psychology.

Sagita, (2015). Effect of Working Capital, Liquidity, Activity, and Company Size on Profitability. University of Education.

Sarafino, E. P. (1990). Health Psychology. Singapore. John Wiley and Sons. Smet.

Slameto. (2003). Learning and Factors Affecting It. Jakarta: Rineka Cipta.

Smet, (1994). Health Psychology. Jakarta: Gramedia Widiasarana Indonesia.

Syafaruddin \& Irwan, N. (2005). Learning Management. Jakarta: Quantum.

Van Erde, W. (2003). A Meta Analytically Derived Nomological Network of. Procrastination. Personality and Individual Differencess 35 (2003) 1401.

Wulan Rujiati. (1994). Malay Codicology in Indonesia. Depok: Faculty of Letters Universitas Gajah Mada.

Zulkaida. (2007). "The Effect of Locus of Control and Self-Eficacy on Career Maturity of High School Students 39. Jakarta". Journal of Proceeding Rapidly, 32 (2), 115-117. 